\title{
Dopaminergic regulation of feeding behavior: I. Differential effects of haloperidol microinfusion into three striatal subregions
}

\author{
V. P. BAKSHI and A. E. KELLEY \\ Harvard University, Cambridge, Massachusetts
}

\begin{abstract}
In the present study, the role of dopaminergic mechanisms within different striatal subregions in feeding behavior was examined in food-deprived $(19 \mathrm{~h})$ rats. Specifically, the dopamine (DA) antagonist haloperidol $(0,0.025,0.25,2.5 \mu \mathrm{g} / 0.5 \mu \mathrm{l})$ was infused bilaterally into the nucleus accumbens (N.Acc.), the ventrolateral striatum (VLS), or the dorsolateral striatum (DLS), and a microanalysis of ingestive behavior and spontaneous motor behavior was carried out. When infused into the N. Acc., haloperidol increased feeding duration, food intake, and the average duration of a feeding bout. Locomotor activity and drinking behavior were reduced by N.Acc. haloperidol infusion. In contrast, feeding was attenuated when haloperidol was infused into the VLS. Drinking and locomotion were unaffected. Few changes in ingestive behavior were noted following DA-antagonist treatment of the dorsolateral site. It is hypothesized that DA transmission in the N.Acc. normally facilitates switching between different competing behaviors, that the VLS is critical for control of oral motor mechanisms, and that the DLS is minimally involved in modulating ingestive behavior.
\end{abstract}

Since Ungerstedt's (1971) classic study of the severe aphagia and adipsia resulting from 6-OHDA lesions of the central dopamine systems, a considerable amount of attention has been focused on the relationship between dopamine and motivation. Although it is widely held that dopamine plays a critical role in motivated behaviors, the precise nature of this role has eluded investigators. Much work has been directed at understanding the behavioral deficits arising from neuroleptic treatment. Dopamine antagonists impair a wide range of instrumental and spontaneous motor behaviors, such as operant responding for food or brain stimulation, conditioned avoidance responses, conditioned appetitive responses, and locomotor activity (e.g., Beninger \& Phillips, 1980; Blackburn, Phillips, \& Fibiger, 1987; Ettenberg, 1989; Fibiger, Carter, \& Phillips, 1976; Fibiger, Zis, \& Phillips, 1975; Heyman, Kinzie, \& Seiden, 1986; Irwin, Tombaugh, Zacharko, \& Anisman, 1983; Salamone, 1986). The first study that suggested that reinforcement processes may be affected by neuroleptics was carried out by Olds and Travis (1960), who found that reinforcing lateral hypothalamic brain stimulation was reduced by chlorpromazine. Wise, Spindler, DeWit, \& Gerber (1978) then developed an important theory, which became known as the anhedonia hypothesis. Wise et al. put forward the notion that the central dopamine neurons mediated the hedonic properties

This research was supported by Grant BNS-9008976 from the National Science Foundation and by a Ford Foundation undergraduate research award to the first author. Correspondence may be sent to either author at the Department of Psychology, 125 Nightingale Hall, Northeastern University, Boston, MA 02115. of reinforcers such as food, brain stimulation, and psychostimulant drugs. According to this hypothesis, the rewarding impact of both primary and secondary reinforcers is blunted by the blockade of dopaminergic transmission, and this effect accounts for the reductions in behavior that are observed.

Early criticism of this hypothesis stressed that the motor deficits that neuroleptics induced could not be dismissed, and there was considerable disagreement as to whether responding under the effects of a neuroleptic and responding in extinction were functionally equivalent (Beninger, 1982; Ettenberg \& Camp, 1986; Salamone, 1986; Tombaugh, Anisman, \& Tombaugh, 1980). More recent formulations have tried to address the motor-motivational issue by suggesting that dopamine is critical for the process by which motivationally significant stimuli "activate" or energize specific motor behaviors elicited by rewards but not for the perception of primary rewards (Beninger, 1983; Fibiger \& Phillips, 1986; Mogenson \& Phillips, 1976; Salamone, in press). This idea, which recognizes the difficulty of separating motivational and motor processes, has its roots in the framework of incentive-motivation theory (Bindra, 1968; Bolles, 1972; Killeen, Hanson, \& Osbourne, 1978).

The effects of dopamine antagonists on ingestive behavior, which is the focus of the present study, has been the subject of several studies. Blackburn et al. (1987) found that treatment with pimozide blocked "preparatory" behavior (behavior associated wit food-related cues) elicited by a conditional stimulus but left feeding intact. On the other hand, several studies have shown that treat- 
ment with a neuroleptic does disrupt feeding when food is available in a foraging situation (Salamone, 1988) or when it is delivered in time-limited meal segments (Wise $\&$ Colle, 1984). Yet other earlier studies have reported increased feeding after neuroleptic treatment (Stolerman, 1970), and patients treated with neuroleptics can show increased eating and weight gain (Blundell, 1987; Robinson, McHugh, \& Folstein, 1975). Thus, there is considerable controversy in the literature as to precisely how feeding behavior is affected by dopamine-receptor blockade.

One problem that appears to have been overlooked in many studies of neuroleptics is the functional heterogeneity of the striatal dopamine system. There is much evidence from studies of the organization of afferent inputs, as well as from lesion experiments, that the striatum is composed of functional subregions, or segregated circuits (Alexander, DeLong, \& Strick, 1986). Since dopaminergic neurons arising from the midbrain innervate the entire expanse of neostriatum, blockade of their corresponding receptors with a systemic injection of neuroleptic would affect all subregions of the dopamine system. Thus, any global behavioral deficits are necessarily a result of interference in many areas that normally may have quite different functions. An alternative way of approaching this problem is the use of central microinjections directed at subregions of the striatal dopamine system. In the present study, we used this approach by investigating the effects of striatal microinjections of haloperidol on free-feeding behavior. The sites studied were the nucleus accumbens, the ventrolateral striatum, and the dorsolateral striatum. These sites were chosen on the basis of evidence for differential anatomical connections, as well as for dissociable behavioral functions. The nucleus accumbens, in the anteroventromedial sector of striatum, receives a projection from the hippocampal formation, as well as fiber input from the amygdala and the medial frontal cortex (Beckstead, 1979; Kelley \& Domesick, 1982; Kelley, Domesick, \& Nauta, 1982). Dopaminergic innervation in this structure has traditionally been considered critical for reinforcement processes. The ventrolateral striatum is distinguished by its strong projections from the amygdala, as well as from the perirhinal and insular cortex (Beckstead, 1979; Kelley et al., 1982) and from a midbrain projection from A8 and lateral A10 cell groups (Deutch, Baldino, Goldstein, \& Roth, 1988). Recently, it has been demonstrated that this site plays a critical role in oral behaviors and possibly feeding (Kelley, Gauthier, \& Lang, 1989; Kelley, Lang, \& Gauthier, 1988). The third site, the dorsolateral striatum, is unique in that it receives virtually no input from limbic structures and is innervated almost exclusively by sensorimotor cortex (Kelley et al., 1982). Lesion and microinjection studies suggest that its role may lie in the domain of sensorimotor and postural functions. In the following experiments, an analysis of feeding was carried out in fooddeprived rats, following the microinjection of haloperidol into these three subregions. In order to gain the maximum amount of information, a microanalysis of both food intake and feeding and drinking patterns was carried out.

\section{METHOD}

\section{Subjects}

Eight male Sprague-Dawley rats (Charles River) weighing 300-350 g were used in each of three experiments. Animals were maintained individually in clear plastic cages with wire grid floors and kept on a 12:12-h light:dark cycle with lights on at $0800 \mathrm{~h}$. They were given access to food ad lib (Agway Rat Chow) and water, except for the day before the test session. Food was removed $19 \mathrm{~h}$ prior to each testing session and was replaced immediately after the session.

\section{Surgical Procedures}

Rats were anesthetized with sodium chloral hydrate $(60 \mathrm{mg} / \mathrm{ml}$, initial dose $1.3 \mathrm{ml}$ ). They were secured in a Kopf stereotaxic apparatus, and bilateral stainless steel cannula guides (23-ga) were implanted at the appropriate sites, which are described below. Coordinates were determined by using the atlas of Pellegrino and Cushman (1967). For implantation in the nucleus accumbens, the coordinates were $3.5 \mathrm{~mm}$ anterior to bregma, $1.7 \mathrm{~mm}$ lateral to midline, and $5.7 \mathrm{~mm}$ ventral from skull. The coordinates for the ventrolateral striatal site were $2.0 \mathrm{~mm}$ anterior to bregma, $4.0 \mathrm{~mm}$ lateral to midline, and $4.7 \mathrm{~mm}$ ventral from skull. The coordinates for the dorsolateral site were $2.7 \mathrm{~mm}$ anterior to bregma, $3.0 \mathrm{~mm}$ lateral to midline, and $3.4 \mathrm{~mm}$ ventral from skull. Guide cannulas were affixed to the skull with light-curable dental resin. Wire stylets were inserted into the guide cannulas to prevent occlusion. Animals were allowed a recovery period of 3 days before behavioral testing.

\section{Microinjections and Drug Preparation}

Bilateral injection cannulas (30-ga) were lowered through the skull cannulas to the desired site. For the nucleus accumbens (N.Acc.) and ventrolateral striatum (VLS) infusions, injection cannulas were lowered $2.5 \mathrm{~mm}$ beyond the guide cannula tip, reaching to $8.2 \mathrm{~mm}$ and $7.2 \mathrm{~mm}$ below the skull, respectively. For the dorsolateral striatum (DLS) infusions, injection cannulas were lowered $1.5 \mathrm{~mm}$ beyond the guide cannulas, reaching to $4.9 \mathrm{~mm}$ below the skull. The injection cannulas were connected via polyethylene tubing to a microdrive pump (Harvard Apparatus) which delivered the drug over a 93-sec period. A volume of $0.5 \mu \mathrm{l}$ of solution was administered to each side. After drug infusion, a 1-min diffusion period was allowed before the removal of the needles and the replacement of the stylets. Animals were loosely held by the experimenter throughout the injection procedure. All drugs were dissolved in Hanks's balanced salt solution (Whittaker Bioproducts). One preliminary injection of vehicle was carried out, before all experimental testing, to adapt the rats to the microinjection procedure. Each experiment consisted of 4 test days, which were separated by intervals of 1 day. Haloperidol (injectable form, QUAD Pharmaceuticals) was infused into one of the three brain sites described above. The doses were $0.025,0.25$, and $2.5 \mu \mathrm{g} /$ side for all sites. All doses are given as the amount dissolved in $0.5 \mu$ l of Hanks's solution. Administration of the three drug doses and vehicle was counterbalanced for order.

\section{Behavioral Testing}

The rats were habituated to the observation room for $2 \mathrm{~h}$ on the day prior to testing. A sheet of blank white paper was placed beneath each cage grid to familiarize the rats with its presence during testing. Experimentation was carried out between 1100 and $1500 \mathrm{~h}$. Immediately prior to injection, the paper was placed under the cage 
grid to catch spilled food. Animals were injected and placed back into their home cages. Cages were brought into the testing room, and four food pellets were scattered along the cage grid. Behavioral monitoring began immediately after food dispersal and replacement of the cage lid. An event recorder linked to a Eurobeeb microcomputer (Paul Fray, Ltd, Cambridge, U.K.) was used continuously throughout the 30-min session to measure spontaneous motor and ingestive behaviors. The parameters recorded were locomotion (crossing over cage center), feeding, and drinking. The frequency, total duration (in seconds), and mean duration (in sec) of these behaviors were recorded, except for locomotion, for which only frequency was recorded. The frequency for feeding and drinking was termed "number of bouts" (the number of times an animal picked up food and commenced feeding, or started drinking). Latencies to initiate feeding and drinking were also recorded. The mean duration of a behavior was calculated as the total duration (in seconds) divided by the frequency. Feeding rate (total food ingested divided by total feeding time, resulting in a measure of grams/minute), total food ingested (grams), and total food spilled (grams) during the trial were calculated after the test session. Food spillage was collected on the sheet of paper beneath the cage. Frequency data sheets were used in addition to the event recorder to note stereotypic or other spontaneous behaviors. The rater entered a 1 for the presence of a certain behavior and a 0 for the absence of that behavior. Behaviors monitored included biting, sniffing with head up, sniffing with head down, gnawing directed at self, and licking. These behaviors were monitored every $5 \mathrm{~min}$ for a 1 -min observation period. At all times, the observer was blind to pharmacological treatment.

\section{Histology}

After completion of the experiment, rats were deeply anesthetized with Nembutal and perfused transcardially with isotonic saline followed by $10 \%$ formalin. The brains were removed and stored in $10 \%$ formalin for a few days. The brains were then frozen and cut into $60-\mu \mathrm{m}$ sections by using a sliding microtome. The slices were mounted, defatted, and stained with cresyl violet. Sections were examined under a tissue projector to determine the accuracy of the cannula placements.

\section{Data Analysis}

An analysis of variance was performed on scores for spontaneous motor behavior, followed by Newman-Keuls comparisons be- tween means. Because the data for ingestive behavior were at times highly variable and not normally distributed, these data were analyzed with the use of the Wilcoxon signed-ranks test. To legitimately carry out multiple pairwise comparisons between doses, a Bonferroni adjustment procedure was used. The acceptable alpha level for statistical significance is made more stringent by dividing the normal level $(p<.05)$ by the number of desired comparisons. Since in the present study there were always 3 comparisons of interest (comparing vehicle with 3 doses), .05 was divided by 3 , resulting in $p<.02$. Thus, effects had to reach $p<.02$ to be considered significant.

\section{RESULTS}

\section{Spontaneous Motor Behavior}

The highest dose of haloperidol $(2.5 \mu \mathrm{g})$ significantly decreased locomotor activity following infusion into the N.Acc. $(p<.014$, Wilcoxon signed-ranks tests), as shown in Figure 1. Figure 1 also shows that locomotor scores were not significantly affected by drug administration into the VLS or DLS. For all groups, no other changes in orofacial behavior or stereotypies were noted.

\section{Ingestive Behaviors}

Figure 2 illustrates the effect of haloperidol treatment on food intake. Following injections into the N.Acc., total gram food intake tended to increase with increasing drug dosage, although the trend did not quite reach statistical significance according to the present criteria $(p<.058$ for saline vs. the 2.5- $\mathrm{g}$ dose). The opposite effect was observed following drug infusion into the VLS. At this site, food intake was significantly reduced by both the middle and high doses of haloperidol $(p<.009)$. Food intake in rats receiving dorsolateral striatal injections was not significantly affected by drug infusion.

In response to haloperidol treatment, total feeding duration followed the same trends as total food intake (Figure 3). A dose-dependent enhancement in feeding dura-

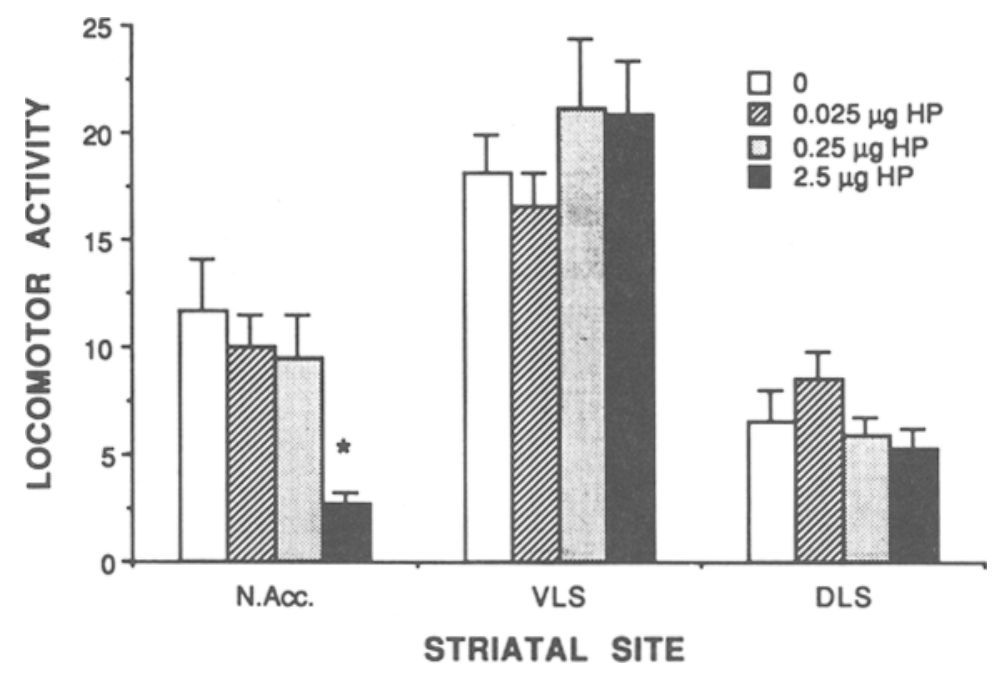

Figure 1. Effects of haloperidol (HP) infused into nucleus accumbens (N.Acc.), ventrolateral striatum (VLS), and dorsolateral striatum (DLS) on locomotor activity. ${ }^{*} p<.02$. 


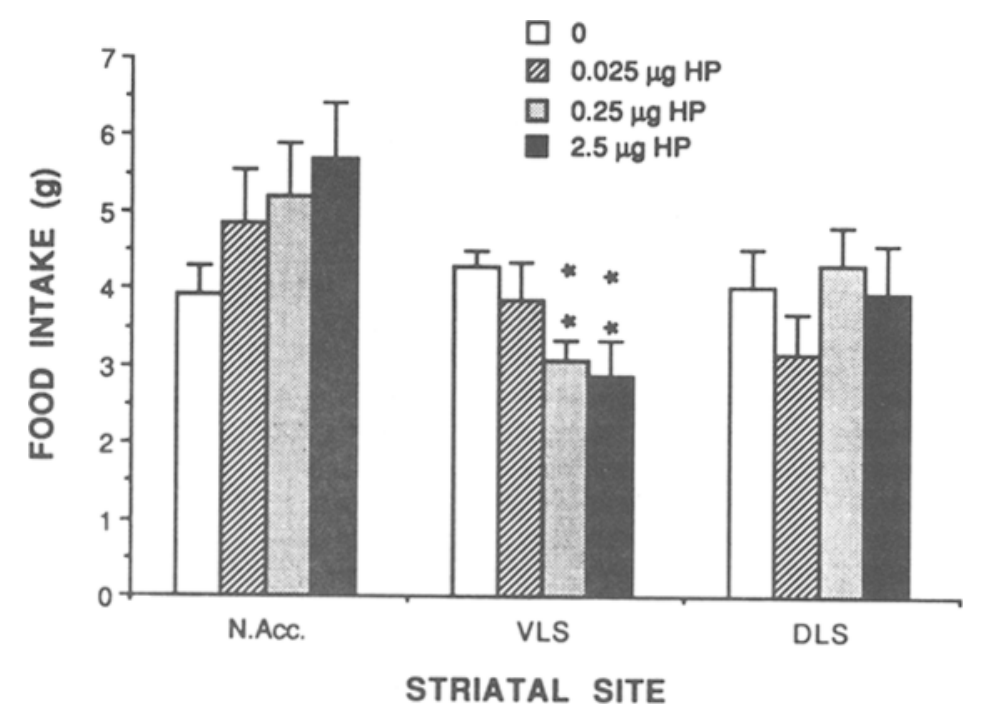

Figure 2. Food intake in grams (g) following infusion of haloperidol (HP) into nucleus accumbens (N.Acc.), ventrolateral striatum (VLS), and dorsolateral striatum (DLS). Animals were deprived of food for $19 \mathrm{~h}$ prior to the test session. ${ }_{p}<.01$.

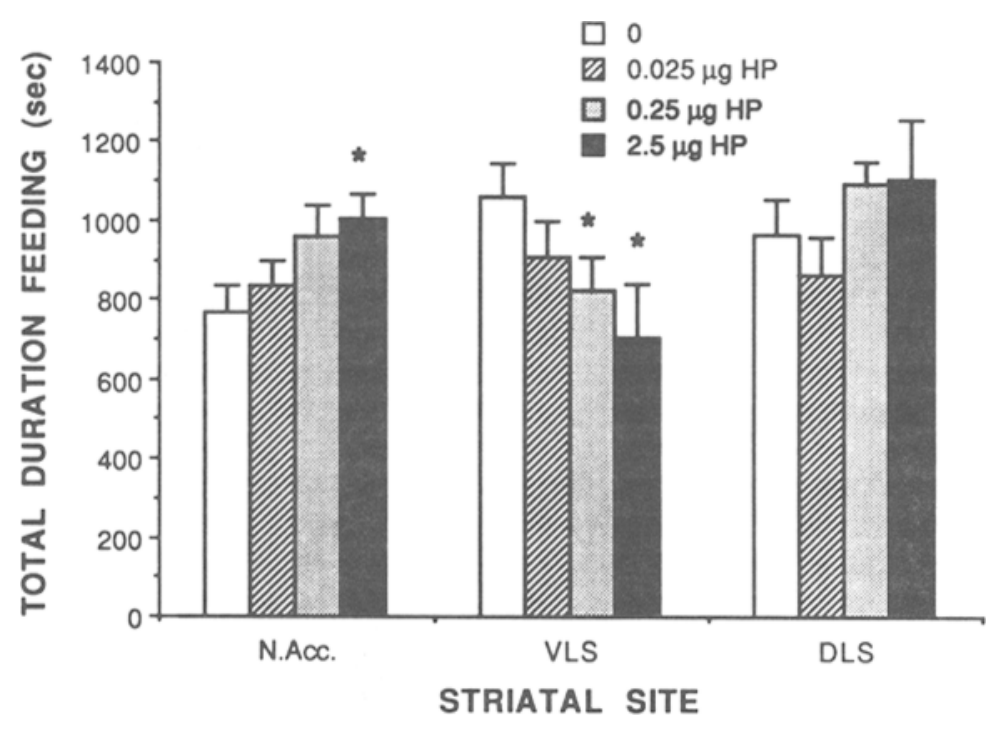

Figure 3. Total feeding duration in seconds following infusion of haloperidol into nucleus accumbens (N.Acc.), ventrolateral striatum (VLS), and dorsolateral striatum (DLS). ${ }^{* p}<.02$.

tion occurred following drug infusion into the N.Acc. The highest dose increased feeding duration significantly $(p<.014)$. In rats receiving injections into the VLS, feeding duration decreased with increasing drug dosage. Both the medium and the high doses of haloperidol attenuated feeding duration $(p<.02)$. Drug infusion into the DLS had no effect on feeding duration.

Other feeding parameters are shown in Table 1. For the N.Acc. group, mean duration of a feeding bout (total duration/bouts) was significantly increased by the $2.5-\mu \mathrm{g}$ dose of haloperidol $(p<.02)$. No other feeding parameters were affected in this group. For the VLS group, there were no further alterations of feeding (Table 1). Following haloperidol injections into the DLS, most other feeding parameters were not affected. However, there was a significant reduction in the number of feeding bouts, which was induced by the highest dose $(p<.009)$. As can be noted from Table 1, this group had a considerably lower baseline of feeding bouts than the other groups (see Discussion). This group also showed a tendency 
Table 1

Effect of Haloperidol Infusion into Striatal Subregions on Other Feeding Parameters

\begin{tabular}{|c|c|c|c|c|c|c|c|c|c|}
\hline \multirow[b]{2}{*}{ Treatment } & \multicolumn{2}{|c|}{ Bouts } & \multicolumn{2}{|c|}{$\begin{array}{c}\text { Mean Bout } \\
\text { Duration }(\mathrm{sec})\end{array}$} & \multicolumn{2}{|c|}{ Spillage (g) } & \multicolumn{2}{|c|}{$\begin{array}{c}\text { Feeding Rate } \\
(\mathrm{g} / \mathrm{min})\end{array}$} & \multirow{2}{*}{$\begin{array}{c}\text { Median Latency } \\
\text { to Initiate } \\
\text { Feeding (sec) }\end{array}$} \\
\hline & $M$ & $S E M$ & $M$ & $S E M$ & $M$ & $S E M$ & $\boldsymbol{M}$ & $S E M$ & \\
\hline \multicolumn{10}{|c|}{ N.Acc. $(n=6)$} \\
\hline Vehicle & 28 & 4 & 33 & 9 & 1.03 & 0.20 & 0.30 & 0.02 & 58 \\
\hline $0.025 \mu \mathrm{g} \mathrm{HP}$ & 28 & 1 & 30 & 3 & 1.18 & 0.20 & 0.35 & 0.06 & 64 \\
\hline $0.25 \mu \mathrm{g} \mathrm{HP}$ & 25 & 2 & 39 & 4 & 1.16 & 0.36 & 0.34 & 0.05 & 78 \\
\hline $2.5 \mu \mathrm{g} \mathrm{HP}$ & 23 & 5 & $60^{*}$ & 17 & 0.98 & 0.17 & 0.33 & 0.03 & 48 \\
\hline \multicolumn{10}{|c|}{ VLS $(n=8)$} \\
\hline Vehicle & 21 & 2 & 54 & 8 & 0.71 & 0.16 & 0.25 & 0.01 & 99 \\
\hline $0.025 \mu \mathrm{g} \mathrm{HP}$ & 24 & 3 & 44 & 8 & 0.94 & 0.31 & 0.26 & 0.05 & 70 \\
\hline $0.25 \mu \mathrm{g} \mathrm{HP}$ & 20 & 3 & 46 & 7 & 0.72 & 0.18 & 0.23 & 0.01 & 106 \\
\hline $2.5 \mu \mathrm{g} \mathrm{HP}$ & 23 & 6 & 51 & 21 & 0.72 & 0.18 & 0.26 & 0.02 & 87 \\
\hline \multicolumn{10}{|c|}{$\operatorname{DLS}(n=8)$} \\
\hline Vehicle & 16 & 2 & 63 & 6 & 0.59 & 0.22 & 0.25 & 0.02 & 70 \\
\hline $0.025 \mu \mathrm{g}$ HP & 17 & 4 & 80 & 23 & 0.42 & 0.08 & 0.22 & 0.03 & 39 \\
\hline $0.25 \mu \mathrm{g} \mathrm{HP}$ & 15 & 3 & 117 & 38 & 0.65 & 0.13 & 0.24 & 0.02 & 82 \\
\hline $2.5 \mu \mathrm{g} \mathrm{HP}$ & $11 \dagger$ & 2 & 148 & 57 & 0.64 & 0.07 & 0.21 & 0.02 & 39 \\
\hline
\end{tabular}

Note-N.Acc. = nucleus accumbens, VLS $=$ ventrolateral striatum, DLS $=$ dorsolateral striatum, HP $=$ haloperidol. All parameters shown represent the mean $\pm S E M$ for each treatment. Median latencies were calculated for the latency to initiate feeding because of the large variation in values within any treatment. $* p<.02 . \dagger p<.01$.

Table 2

Effect of Haloperidol Infusion into Striatal Subregions on Drinking Parameters

\begin{tabular}{|c|c|c|c|c|c|c|c|}
\hline \multirow[b]{2}{*}{ Treatment } & \multicolumn{2}{|c|}{ Bouts } & \multicolumn{2}{|c|}{$\begin{array}{c}\text { Total } \\
\text { Duration }(\mathrm{sec})\end{array}$} & \multicolumn{2}{|c|}{$\begin{array}{c}\text { Mean Bout } \\
\text { Duration }(\mathrm{sec}) \\
\end{array}$} & \multirow{2}{*}{$\begin{array}{c}\text { Median Latency } \\
\text { to Initiate } \\
\text { Drinking (sec) }\end{array}$} \\
\hline & $M$ & SEM & $M$ & $S E M$ & $M$ & $S E M$ & \\
\hline \multicolumn{8}{|c|}{ N.Acc. $(n=6)$} \\
\hline $\begin{array}{l}\text { Vehicle } \\
0.025 \mu \mathrm{g} \mathrm{HP} \\
0.25 \mu \mathrm{g} \mathrm{HP} \\
2.5 \mu \mathrm{g} \mathrm{HP}\end{array}$ & $\begin{array}{l}7.0 \\
3.6 \\
2.3 \\
1.7^{*}\end{array}$ & $\begin{array}{l}1.2 \\
1.9 \\
1.0 \\
0.9\end{array}$ & $\begin{array}{l}186 \\
133^{*} \\
103 \\
57^{*}\end{array}$ & $\begin{array}{l}39 \\
43 \\
35 \\
27\end{array}$ & $\begin{array}{l}27 \\
47 \\
49 \\
21\end{array}$ & $\begin{array}{r}2 \\
18 \\
20 \\
11\end{array}$ & $\begin{array}{c}797 \\
880 \\
594 \\
1,759^{*}\end{array}$ \\
\hline \multicolumn{8}{|c|}{ VLS $(n=8)$} \\
\hline $\begin{array}{l}\text { Vehicle } \\
0.025 \mu \mathrm{g} \mathrm{HP} \\
0.25 \mu \mathrm{g} \mathrm{HP} \\
2.5 \mu \mathrm{g} \mathrm{HP}\end{array}$ & $\begin{array}{l}4.4 \\
5.7 \\
4.9 \\
2.4\end{array}$ & $\begin{array}{l}1.8 \\
0.8 \\
1.7 \\
1.3\end{array}$ & $\begin{array}{r}97 \\
136 \\
92 \\
79\end{array}$ & $\begin{array}{l}31 \\
16 \\
29 \\
35\end{array}$ & $\begin{array}{l}24 \\
24 \\
16 \\
27\end{array}$ & $\begin{array}{r}12 \\
2 \\
7 \\
14\end{array}$ & $\begin{array}{l}792 \\
376 \dagger \\
1,382 \\
1,441\end{array}$ \\
\hline \multicolumn{8}{|c|}{$\operatorname{DLS}(n=8)$} \\
\hline Vehicle & 7.5 & 3.3 & 181 & 43 & 39 & 13 & 570 \\
\hline $0.025 \mu \mathrm{g}$ HP & 8.6 & 3.4 & 205 & 69 & 26 & 5 & 410 \\
\hline $0.25 \mu \mathrm{g} \mathrm{HP}$ & 8.4 & 3.4 & 201 & 44 & 31 & 9 & 499 \\
\hline $2.5 \mu \mathrm{g} \mathrm{HP}$ & 6.1 & 2.2 & 167 & 41 & 31 & 8 & 553 \\
\hline
\end{tabular}

Note-N.Acc. = nucleus accumbens, VLS = ventrolateral striatum, DLS = dorsolateral striatum, $\mathrm{HP}=$ haloperidol. All parameters shown, except for latency to initiate drinking, represent the mean $\pm S E M$ for each treatment. Median latencies were calculated for the latency to initiate drinking because several animals did not drink. The highest possible latency, $1,800 \mathrm{sec}$, was assigned to these animals. ${ }^{*} p<.02$. $\dagger p<.01$.

toward increased mean duration of feeding bouts; this trend did not reach significance $(p<.05$ for saline vs. $2.5 \mu \mathrm{g})$. The large increase in the mean score for both the $0.25-\mu \mathrm{g}$ and the $2.5-\mu \mathrm{g}$ doses was primarily due to one rat.

The effects of haloperidol treatment on drinking behaviors are shown in Table 2 . A decrease in the number of drinking bouts was observed following haloperidol administration into the N.Acc. $(p<.014$ for saline vs. the 2.5- $\mu \mathrm{g}$ dose). The middle dose of haloperidol also tended to decrease drinking bouts $(p<.03)$. The total duration of drinking was also significantly reduced by haloperidol treatment $(p<.014$ for vehicle vs. $0.025 \mu \mathrm{g}$ and $2.5 \mu \mathrm{g} ; p<.034$ for vehicle vs. $0.25 \mu \mathrm{g}$ ). The latency to initiate drinking was augmented by the $2.5-\mu \mathrm{g}$ dose $(p<.014)$. In contrast, the profile of drinking behavior was not altered by haloperidol infusion into the VLS or the DLS sites. One seemingly anomalous finding was that the lowest dose of haloperidol decreased latency to drink $(p<.009)$ in the VLS group. This group also 


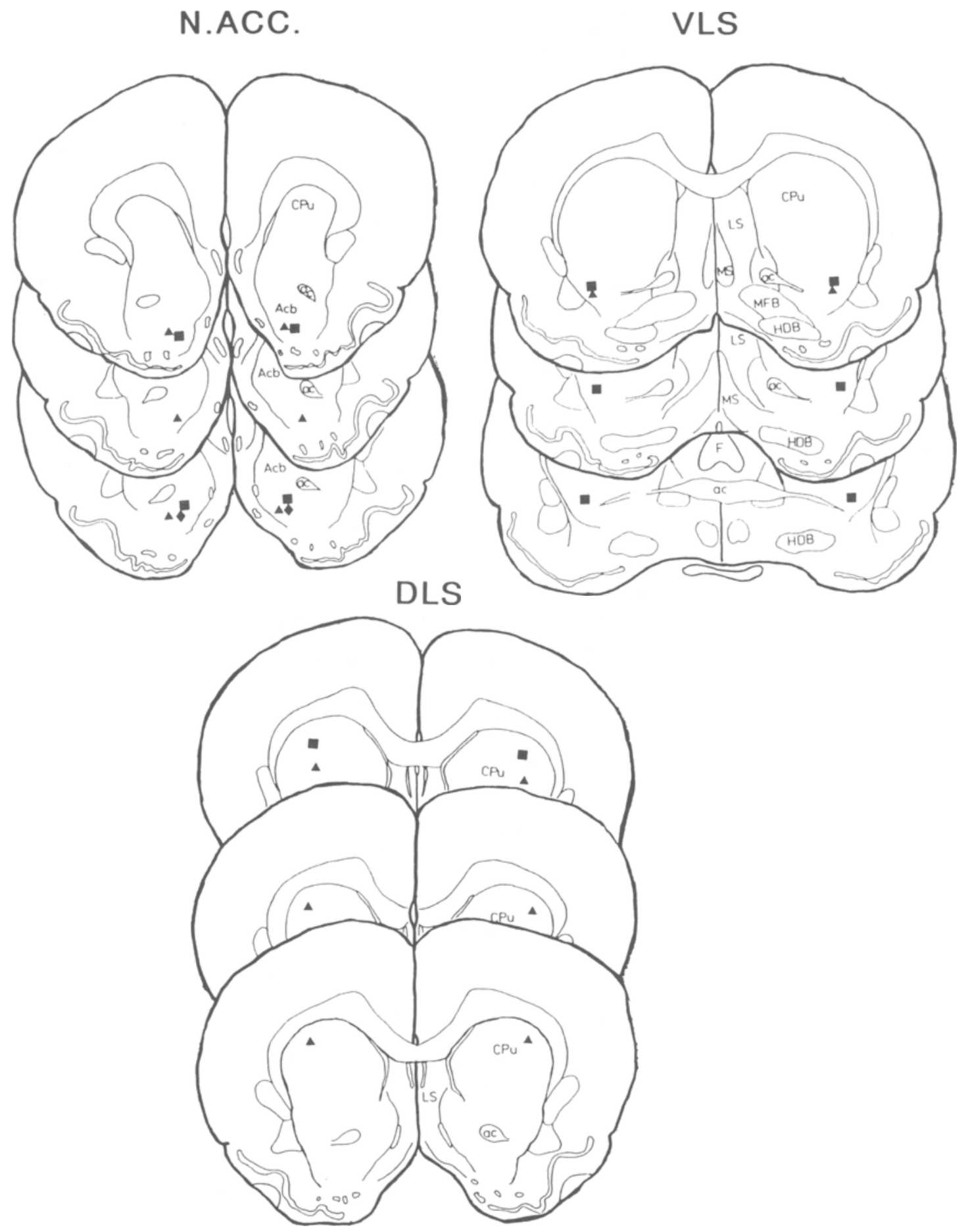

Figure 4. Drawings depicting cannula tip locations within striatal subregions from representative animals. Each pair of symbols represents bilateral placements of one animal. N.Acc. = nucleus accumbens, VLS = ventrolateral striatum, DLS = dorsolateral striatum. 
showed increased latency to drink following the highest dose, although the tendency did not reach significance $(p<.09)$.

\section{Histology}

Representative cannula placements are shown in Figure 4. For all rats studied, cannula placements were found to be localized within the desired striatal zone.

\section{DISCUSSION}

The present results provide convincing evidence for the functional heterogeneity of the striatum with regard to feeding behavior. Blockade of dopamine receptors in different subregions of this structure resulted in dissociable effects on ingestive behavior. Several general conclusions can be made concerning this work. First, haloperidol infused into the N.Acc. tended to make animals feed more and reduced other competing behaviors such as locomotor activity and drinking. Second, haloperidol infused into the VLS reduced food intake and feeding but left locomotion and drinking unaffected. Third, blockade of dopamine (DA) receptors in the DLS produced few changes in feeding. The results, taken together, suggest that the N.Acc. is involved in attentional aspects of feeding, that the VLS is critical for the oral motor control of feeding, and that the DLS is minimally involved in controlling ingestive behavior. These hypotheses are explored further below.

\section{Nucleus Accumbens}

A clear and significant effect of haloperidol infused into this structure was the reduction of motor activity, following administration of the highest dose. The total time spent feeding was increased by haloperidol, and the total amount of intake tended to be increased, although not significantly. Average duration of a feeding bout was increased by the highest dose of haloperidol. That rats tended to feed for longer periods is suggested by the drinking data. The latency to drink was greatly increased in animals treated with the highest dose of haloperidol, and the total duration of time spent drinking was attenuated. This pattern, together with the feeding data, suggests that haloperidol-treated rats switched from feeding to drinking far less than control rats did.

These results demonstrate that blocking DA receptors in the region of the N.Acc. does not reduce feeding in hungry animals. This may appear somewhat surprising in view of the fact that one might expect reduced motivation to feed, as has been hypothesized for effects following systemic injections of neuroleptics (Wise \& Colle, 1984). However, the present findings agree with a number of studies in the literature. Salamone (1988) studied the effects of systemic haloperidol during periodic presentation of food and in a foraging situation. Scheduleinduced motor activity in an operant chamber was reduced by haloperidol, but the rats consumed all of the food delivered. During the more complex situation of foraging, in which the animal had to engage in a food search, feed- ing was disrupted. This suggests that when food is freely available and proximal to the animal, the motivation and ability to feed is not altered. Other work by Salamone (1986) showed that during barpressing on a fixed-ratio schedule for food reward, systemic haloperidol did not decrease the time spent at the food panel, which would have been expected if the motivation for food had been diminished. Tombaugh and colleagues found that although pimozide had subtle effects on alimentary behaviors, actual consumption of food was not affected (Irwin et al., 1983; Tombaugh, Tombaugh, \& Anisman, 1979).

Recent work by Blackburn et al. (1987) suggests that dopamine mediates behaviors closely associated with feeding but does not mediate the consummatory response itself. Thus, these authors showed that pimozide reduced conditioned preparatory responses (entries into a food niche when availability was signaled by a conditional stimulus) but left feeding intact when food was available in a free-feeding situation. Moreover, in biochemical measurements, increased dopaminergic activity was observed in the $\mathrm{N}$.Acc. in association with the presentation of a stimulus signaling food but not with the consummation of food (Blackburn, Phillips, Jakubovic, \& Fibiger, 1989). These authors suggest that dopaminergic mechanisms may be involved in feeding when animals are distant from food but are not directly involved in consumption once animals are in direct contact with food. Our findings from haloperidol injections into the N.Acc., during which animals were observed in a situation with the food in very close proximity, agree with this theory.

On the other hand, it is of interest to note that following haloperidol infusion into the N.Acc., rats actually tend to feed more but show lower levels of presumably competing behaviors, such as drinking and locomotion. These results support several earlier studies of the effects of 6-OHDA lesions of the N.Acc. Koob, Riley, Smith, and Robbins (1978) showed that rats with such lesions, when food-deprived, eat significantly more food than do control rats in restricted 30-min tests of free feeding. Lesioned animals also showed both hypoactivity during the feeding tests and significantly reduced food-associated drinking. Thus, their results agree exactly with the profile reported here, following acute blockade of dopamine in this region. Robbins and Koob (1980) also demonstrated that similar lesions cause thirsty animals to engage in significantly longer drinking bouts. In both studies, it is proposed that mesolimbic dopamine is critical for the activation of behaviors associated with a particular motivational state and also for switching between behaviors during high-arousal states. Thus, we would argue that it is for similar reasons that animals treated with haloperidol in the accumbens feed more and show less drinking and locomotion.

\section{Ventrolateral Striatum}

The greatest effects on ingestive behavior were observed following injections into this region. First, it is important to note that (in contrast to the results with the N.Acc.) 
locomotion was not affected by injection of the drug into the VLS. These animals showed normal locomotor behavior even following the highest dose, which most severely disnupted feeding. Food intake was reduced by both the medium and the high doses of haloperidol, as was feeding duration. Latencies and other feeding parameters were not affected. Drinking was not greatly altered, although erratic results for drinking latency were obtained. The general pattern of behavior contrasts with the pattern found after similar infusions into the N.Acc. Animals in the VLS group showed reduced feeding and little changes in other behaviors, which suggests that the blockade of dopamine receptors in this region may interfere rather specifically with oral motor control. Previous work from this laboratory has shown that this region is selectively involved in oral motor functions. Infusion of low doses of amphetamine into the region (in sated rats) elicits mild stimulation of feeding (Kelley, Gauthier, \& Lang, 1989), and higher doses induce intense oral stereotypy (Kelley et al., 1988). In these studies, infusions of amphetamine into other striatal regions did not affect oral behavior or feeding. Cholinergic stimulation of the VLS, but not of the DLS or N.Acc., produces distinctive mouth movements (Kelley, Bakshi, Delfs, \& Lang, 1989). Furthermore, it has been shown that selective ibotenic lesions of the ventrolateral striatal region affect tongue use in tests of oral motor function (Pisa, 1988). It has also been reported that 6-OHDA lesions of the VLS result in aphagia and adipsia, in contrast to lesions in other striatal sites (Dunnett \& Iversen, 1982). Thus, there is considerable evidence that this particular area of the striatum is critical for oral motor functions, and our present results support this notion. One should note that other brain regions may also influence oral motor responses that are important for feeding. It has been found that lesions of the hypothalamus or of the orbital frontal cortex impair tongue use in rats (Whishaw \& Kolb, 1983).

\section{Dorsolateral Striatum}

Changes in ingestive behavior induced by haloperidol infusions into this region were minimal. Both the level of food intake and the mean duration of feeding bouts tended to be somewhat increased by the highest dose of haloperidol, although these effects did not reach significance. The only statistically significant finding was that the number of feeding bouts was reduced by the highest dose of haloperidol. Also, it should be noted that, on this parameter, the baseline is lower than that of the other two groups. (In the companion paper, feeding bouts are also much lower in the DLS animals; Bakshi \& Kelley, 1991). Rats in the DLS group tended to be less active in general. From other data in this laboratory, we have found that regardless of drug treatment, rats implanted with guide cannulas in this region appear to have general motor deficits. This may arise from the guide's causing the lesion of motor areas of the cortex or striatum. At present, the explanation for the lowered feeding bouts fol- lowing haloperidol is uncertain, but it may relate to the nonspecific motor deficit found in untreated animals.

Overall, the data suggest that the DLS mediates neither the activational nor the specific oral motor functions associated with feeding. The literature suggests that this region tends to be linked to sensorimotor or postural functions. The overlying sensorimotor cortex sends a dense projection here (whereas limbic afferents avoid this region; Kelley et al., 1982). Selective lesions in the dorsolateral region results in sensory neglect (Fairley \& Marshall, 1986; Marshall, Berrios, \& Sawyer, 1980) and disruptions in limb use (Pisa, 1988; Pisa \& Schranz, 1988; Sabol, Neill, Wages, Church, \& Justice, 1985). Furthermore, injections of dopamine into the dorsal area of striatum induces rotation and postural deviation (Joyce \& Van Hartesveldt, 1984). Although the present data suggest that the DLS is not critically involved in the feeding response, they do not rule out the possibility that this region may mediate more subtle motor or sensory functions associated with feeding (such as orientation to food or performance of a complex motor response to obtain food).

\section{Neuroleptics, Feeding, and \\ the Anhedonia Hypothesis}

The so-called anhedonia hypothesis states that the blockade of dopaminergic receptors with neuroleptics results in attenuation or blunting of the rewarding of reinforcers, including food (Wise, 1982). Discussion of this hypothesis in view of the present results is therefore relevant. In several studies in which systemically administered neuroleptics have been found to disrupt ingestive behavior, it has been suggested that such treatment either reduces the motivation to feed or attenuates the rewarding impact of food (Geary \& Smith, 1985; Wise \& Colle, 1984). Furthermore, it is generally assumed that such a motivational deficit results from the reduction of DA transmission in mesolimbic regions, such as the N.Acc. However, it is clear from the present results (also see Koob et al., 1978) that the blockade of DA transmission in this region does not reduce feeding but rather increases it. We would propose that the immediate motivation to feed (driven by such factors as hunger, internal cues, sensory properties of the food, etc.) is not changed by neuroleptic infusion into the N.Acc. However, this does not mean that the "rewarding impact" of the food has not been altered in the presence of neuroleptics (although the present experiments do not address this question). The key point here is what is meant by the term "impact." Other work, in fact, has elegantly demonstrated that neuroleptics block incentive motivational properties of food. For example, Spyraki, Fibiger, and Phillips (1982) found that neuroleptic treatment blocked the development of place conditioning induced by food. Although the animals in this study ate all of the food during conditioning (i.e., under the effects of neuroleptics), the association between the positive properties of food and environmental cues was not formed. Two further studies showed that treatment with neuroleptics reduced response-activating properties of food re- 
inforcement (Horvitz \& Ettenberg, 1989) and that intermittent treatment in a runway for food induced a partial reinforcement extinction effect on later trials (Ettenberg \& Camp, 1986). In both these studies, all rats consumed the food on all trials. Thus, it appears that the factors that underlie consumption of food are not altered by neuroleptic treatment. In contrast, there is evidence that incentive properties of food, which elicit specific food-related motor responses or affect changes in subsequent behavior, are decreased by blockade of DA receptors. A remaining question is whether the sensory or hedonic properties of food are changed by neuroleptics. Although some work has suggested that neuroleptic treatment is equivalent to changes in the perception of the quality of the reinforcer (Geary \& Smith, 1985), other studies do not agree with this claim (Berridge, Venier, \& Robinson, 1989; Ettenberg \& Camp, 1986; Martin-Iverson, Wilkie, \& Fibiger, 1987).

In reviewing the literature on neuroleptics and feeding (which has focused entirely on systemic administration), it is clear that, in many cases, conflicting results have been obtained. The present results may help to explain some of these discrepancies. The motor deficits that sometimes are observed following such treatment may arise from disruption of function in at least two areas. If the feeding situation involves either foraging responses or other preparatory or conditioned behaviors, it is likely that dopaminergic blockade in the N.Acc. accounts for the disruption of these behaviors. When the animal is in contact with the food, neuroleptics (particularly higher doses) may reduce the ability to feed because of deficits in oral motor control. Recent studies of feeding rate following neuroleptic treatment suggest this is so (Salamone et al., 1990). This deficit most likely arises from blockade of the VLS. Blockade or lesions in other striatal regions may affect forepaw control in the manipulation of food (Pisa, 1988; Sabol et al., 1985; Whishaw, O'Connor, \& Dunnett, 1986). Furthermore, large nigrostriatal lesions cause severe aphagia and adipsia (Ungerstedt, 1971), which suggests that the simultaneous destruction of multiple dopamine terminals will completely abolish feeding. Normal ingestive behavior appears to depend on the contributions of several striatal regions. The behavioral effects observed following systemic administration of dopamine blockers is clearly a result of blockade in many of these critical, and differing, areas of striatal function.

\section{REFERENCES}

Alexander, G. E., DeLong, M. R., Strick, P. L. (1986). Parallel organization of functionally segregated circuits linking basal ganglia and cortex. Annual Review of Neuroscience, 9, 357-381.

Bakshn, V. P., Kelley, A. E. (1991). Dopaminergic regulation of feeding behavior: II. Differential effects of amphetamine following microinfusion into three striatal subregions. Psychobiology, 19, 233-242.

BeCKSTEAD, R. M. (1979). An autoradiographic examination of corticocortical and subcortical projections of the mediodorsal-projection (prefrontal) cortex in rats. Journal of Comparative Neurology, 84, 43-62.

BENINGER, R. J. (1982). A comparison of the effects of pimozide and nonreinforcement on discriminated operant responding in rats. Pharmacology, Biochemistry \& Behavior, 16, 667-669.

BENINGER, R. J. (1983). The role of dopamine in locomotor activity and learning. Brain Research Reviews, 6, 173-196

Beninger, R. J., Phillups, A. G. (1980). The effect of pimozide on the establishment of conditioned reinforcement. Psychopharmacology, 68, 147-158.

Berridge, K. C., Venier, I. L., Robinson, T. E. (1989). Taste reactivity analysis of 6-hydroxydopamine-induced aphagia: Implications for arousal and anhedonia hypotheses of dopamine function. Behavioral Neuroscience, 103, 36-45.

BindRA, D. (1968). Neuropsychological interpretation of the effects of drive and incentive-motivation on general and instrumental behavior. Psychological Review, 75, 1-22.

Blackburn, J. R., Phillips, A. G., Fibiger, H. C. (1987). Dopamine and preparatory behavior: 1. Effects of pimozide. Behavioral Neuroscience, 101, 352-360.

Blackburn, J. R., Philuts, A. G., Jakubovic, A., a Fibiger, H. C. (1989). Dopamine and preparatory behavior: II. A neurochemical analysis. Behavioral Neuroscience, 103, 15-23.

BLUNDELL, J. E. (1987). Structure, process and mechanism: Case studies in the psychopharmacology of feeding. In L. L. Iversen, S. D. Iversen, \& S. H. Snyder (Eds.), Handbook of psychopharmacology (Vol. 19, pp. 123-182). New York: Plenum.

Bolses, R. C. (1972). Reinforcement, expectancy and learning. Psychological Review, 79, 394-409.

Deutch, A. Y., Baidino, F., JR., Goldstein, M., \& Roth, R. H. (1988). Telencephalic projections of the A8 dopamine cell group. In P. W. Kalivas \& C. B. Nemeroff (Eds.), The mesocorticolimbic dopamine system. Annals of the New York Academy of Sciences, 537, 27-50.

DUNNETT, S. B., \& IVERSEN, S. D. (1982). Regulatory impairments following selective 6-OHDA lesions of the neostriatum. Behavioral Brain Research, 4, 195-202.

ETTENBERG, A. (1989). Dopamine, neuroleptics and reinforced behavior. Neuroscience \& Biobehavioral Reviews, 13, 105-111.

EttenberG, A., \& CAMP, C. H. (1986). Haloperidol induces a partial reinforcement extinction effect in rats: Implications for a dopamine involvement in food reward. Pharmacology, Biochemistry \& Behavior, 25, 813-821

Fairley, P. C., \&arshall, J. F. (1986). Dopamine in the lateral caudate-putamen of the rat is essential for somatosensory orientation. Behavioral Neuroscience, 100, 652-663.

Fibiger, H. C., CArter, D. A., Phillips, A. G. (1976). Decreased intracranial self-stimulation after neuroleptics or 6-hydroxydopamine: Evidence for mediation by motor deficits rather than by reduced reward. Psychopharmacology, 47, 21-27.

Fibiger, H. C., PHILlips, A. G. (1986). Reward, motivation, cognition: Psychobiology of mesotelencephalic dopamine systems. In V. B. Mountcastle, F. E. Bloom, \& S. R. Geiger (Eds.), Handbook of physiology: The nervous system (Vol. 4, pp. 647-675). Bethesda, MD: American Physiological Society.

Fibiger, H. C., Zis, A. P., \& Phillips, A. G. (1975). Haloperidolinduced disruption of conditioned avoidance responses: Attenuation by prior training or by anticholinergic drugs. European Journal of Pharmacology, 30, 309-314.

Geary, N., Smith, G. P. (1985). Pimozide decreases the positive reinforcing effects of sham fed sucrose in the rat. Pharmacology, Biochemistry \& Behavior, 22, 787-790.

Heyman, G. M., Kinzie, D. L., Seiden, L. S. (1986). Chlorpromazine and pimozide alter reinforcement efficacy and motor performance. Psychopharmacology, 88, 346-353.

Horvirz, J. C., \& ETtenberg, A. (1989). Haloperidol blocks the response-reinstating effects of food reward: A methodology for seperating neuroleptic effects on reinforcement and motor processes. Pharmacology, Biochemistry \& Behavior, 31, 861-865.

IrWin, J., Tombaugh, T. N., Zacharko, R. M., a Anisman, H. (1983). Alteration of exploration and the response to food associated cues after treatment with pimozide. Pharmacology, Biochemistry \& Behavior, 18, 235-246.

JoYCe, J. N., \& VAN HARTESVeldT, C. (1984). Rotational and postural 
deviation responses to microinjections of dopamine into different regions of the dorsal striatum. Pharmacology, Biochemistry \& Behavior, 21, 979-981.

Kelley, A. E., Bakshi, V. P., Delfs, J. M., \&ang, C. G. (1989). Cholinergic stimulation of the ventrolateral striatum elicits mouth movements in rats: Pharmacological and regional specificity. Psychopharmacology, 99, 542-547.

Kelley, A. E., \& Domesick, V. B. (1982). The distribution of the projection from the hippocampal formation to the nucleus accumbens in the rat: An anterograde- and retrograde-horseradish peroxidase study. Neuroscience, 7, 2321-2335.

Kelley, A. E., Domesick, V. B., \& Nauta, W. J. H. (1982). The amygdaloidstriatal projection in the rat-an anatomical study by anterograde and retrograde tracing methods. Neuroscience, 7, 615-630.

Kelley, A. E., Gauthier, A. M., \& Lang, C. G. (1989). Amphetamine microinjections into distinct striatal subregions cause dissociable effects on motor and ingestive behavior. Behavioral Brain Research, 35, 27-39.

Kelley, A. E., Lang, C. G., Gauthier, A. M. (1988). Induction of oral stereotypy following amphetamine microinjection into a discrete subregion of the striatum. Psychopharmacology, 95, 556-559.

Killeen, P., Hanson, S., \& Osbourne, S. (1978). Arousal: Its genesis and manifestation as response rate. Psychological Review, 85, 571-581.

KoOb, G. F., Ruley, S. J., Smith, S. C., \& Robins, T. W. (1978). Effects of 6-hydroxydopamine lesions of the nucleus accumbens septi on feeding, locomotor activity and amphetamine anorexia in the rat. Journal of Comparative \& Physiological Psychology, 92, 917-927.

Marshall, J. F., Berrios, N., SaWyer, S. (1980). Neostriatal dopamine and sensory attention. Joumal of Comparative \& Physiological Psychology, 87, 833-846.

Martin-Iverson, M. T., Wilkie, D., \& Fibiger, H. C. (1987). Effects of haloperidol and $d$-amphetamine on perceived quantity of food and tones. Psychopharmacology, 93, 374-381.

Mogenson, G. J., \& PHillips, A. G. (1976). Motivation: A psychological constnuct in search of a physiological substrate. In J. $\mathbf{M}$. Sprague \& A. N. Epstein (Eds.), Progress in physiological psychology (pp. 189-243). New York: Academic Press.

OLDS, J., Travis, R. P. (1960). Effects of chlorpromazine, meprobamate, pentobarbital, and morphine on self-stimulation. Joumal of Pharmacology \& Experimental Therapeutics, 128, 397-404.

Pellegrino, L. J., Cushman, A. I. (1967). A stereotaxic atlas of the rat brain. New York: Appleton-Century-Crofts.

PISA, M. (1988). Motor functions of the striatum in the rat: Critical role of the lateral region in tongue and forelimb reaching. Neuroscience, 24, 453-463.

Pisa, M., \& SChranz, J. A. (1988). Dissociable motor roles of the rat's striatum conform to a somatopic model. Behavioral Neuroscience, $102,429-440$

Robrins, T. W., \& КоOв, G. F. (1980). Selective disruption of displacement behaviour by lesions of the mesolimbic dopamine system. Nature, 285, 409-412.
Robinson, R. G., McHugh, P. R., \& Folstein, M. F. (1975). Measurement of appetite disturbances in psychiatric disorder. Jourmal of Psychiatric Research, 12, 59-68.

SAbol, K. E., Neill, D. B., Wages, A. A., Church, W., a Justice, J. B. (1985). Dopamine depletion in striatal subregion disrupts performance of a skilled motor task in the rat. Brain Research, 335, 33-43.

SALAMONE, J. D. (1986). Different effects of haloperidol and extinction on instrumental behaviours. Psychopharmacology, 88, 18-23.

SALAMONE, J. D. (1988). Dopaminergic involvement in activational aspects of motivation: Effects of haloperidol on schedule-induced activity, feeding, and foraging in rats. Psychobiology, 16, 196-206.

SALAMONE, J. D. (in press). Behavioral pharmacology of dopamine systems: A new synthesis. In P. Willner \& J. Scheel-Kruger (Eds.), The mesolimbic dopamine system: From motivation to action. New York: Cambridge University Press.

Salamone, J. D., Zigmond, M. J., \& Stricker, E. M. (1990). Characterization of the impaired feeding behavior in rats given haloperidol or dopamine-depleting brain lesions. Neuroscience, 39, 17-24.

Spyrakı, C., Fibiger, H. C., \& Phillips, A. G. (1982). Attenuation by haloperidol of place preference conditioning using food reinforcement. Psychopharmacology, 77, 379-382.

StolermaN, I. P. (1970). Eating, drinking and spontaneous activity in rats after the administration of chlorpromazine. Neuropharmacology, 9, 405-411.

Tombaugh, T. N., Anisman, H., Tombaugh, J. (1980). Extinction and dopamine blockade after intermittent reinforcement training: Failure to observe functional equivalence. Psychopharmacology, 70, 19-28.

Tombaugh, T. N., Tombaugh, J., Anisman, H. (1979). Effects of dopamine receptor blockade on alimentary behaviors: Home cage food consumption, magaxine training, operant acquisition, and performance. Psychopharmacology, 66, 219-225.

UNGERSTEDT, U. (1971). Adipsia and aphagia after 6-hydroxydopamine induced degeneration of the nigro-striatal dopamine system. Acta Physiologica Scandinavica, 367(Suppl. 367), 95-122.

Whishaw, 1. Q., KolB, B. (1983). "Stick out your tongue": Tongue protrusion in neocortex and hypothalamic damaged rats. Physiology \& Behavior, 30, 471-480.

Whishaw, I. Q., O'Connor, W. T., DUnNetT, S. B. (1986). The contributions of motor cortex, nigrostriatal dopamine and caudateputamen to skilled forelimb use in the rat. Brain, 109, 805-843.

WiSE, R. A. (1982). Neuroleptics and operant behavior: The anhedonia hypothesis. Behavioral \& Brain Sciences, 5, 39-87.

Wise, R. A., Colle, L. M. (1984). Pimozide attenuates free feeding: Best scores analysis reveals a motivational deficit. Psychopharmacology, 84, 446-451.

WISE, R. A., SPINDler, J., DeWIt, H., Gerber, G. J. (1978). Neuroleptic-induced "anhedonia"' in rats: Pimozide blocks reward quality of food. Science, 201, 262-264.

(Manuscript received January 30, 1991; revision accepted for publication June 6, 1991.) 